\title{
Impact of Real-Time Contrast-Enhanced Ultrasound-Guided Radiofrequency Ablation on Progression-Free Survival in Patients with Hepatocellular Carcinoma: a Retrospective Case-Control Study
}

\author{
Xiao Shang, Guang Yang, Heng Jun Zhao, Ming Zhang, Guo Zhen Cui, Jiu Wei Cui, Nan Ya Wang\#
}

Cancer Center of the First Hospital, Jilin University, Jilin 130021, Changchun, China

\begin{abstract}
Objective To compare the value of contrast-enhanced ultrasound (CEUS) and conventional ultrasound (US) during radiofrequency ablation (RFA) for the treatment of hepatocellular carcinoma (HCC) $\geq 3.0 \mathrm{~cm}$ in diameter. Methods A total of 149 HCC patients treated with RFA guided by either CEUS or conventional US between January 2012 and June 2013 were retrospectively analyzed. Patients were divided into different groups based on the type of ultrasound guidance (CEUS or conventional US) and tumor volume (diameter $<3.0$ or $\geq 3.0 \mathrm{~cm}$ ). The progressionfree survival (PFS) and complete ablation rates were compared between groups, and risk factors for the PFS were investigated. Results Seventy four patients received CEUS-guided RFA, and conventional US was performed in 75 patients. Among patients with a tumor $<3.0 \mathrm{~cm}$, the PFS and complete ablation rates were similar. However, for patients with a tumor $\geq 3.0 \mathrm{~cm}$, those treated with CEUS had a significantly longer PFS $(17.3$ vs. 3.1 months, HR $=2.73 ; 95 \%$ CI, $1.28 \sim 5.81 ; P=0.007)$ and higher complete ablation rates at 6 - and 12 -month post-treatment $(87.5 \%$ vs. $57.7 \%, P$ $=0.042 ; 75.0 \%$ vs. $38.5 \%, P=0.009$, respectively) than those treated with conventional US-guided RFA. The type of treatment $(P=0.024)$ and maximum tumour size $(P=0.011)$ were both found to be independent factors associated with the PFS. Conclusion Compared with conventional US, CEUS is more effective for guiding RFA in patients with HCC $\geq 3.0 \mathrm{~cm}$. CEUS-guided RFA could target HCC more accurately, and its ability to immediately detect any residual tumor during RFA might contribute to an increase in complete ablation rates and reduced progression.
\end{abstract}

Key words: Hepatocellular carcinoma; Radiofrequency ablation; Contrast-enhanced ultrasound; Conventional ultrasound; Progression-free survival; Complete ablation rate

\section{Introduction}

Hepatocellular carcinoma (HCC) is the fourth leading cause of cancer-related death worldwide, and the incidence is especially high in China [1,2]. Owing to the development of screening programs for patients at high risk, patients are being increasingly diagnosed with small HCC lesions (maximum diameter of tumor $\leq 3.0 \mathrm{~cm}$ ) [3]. However, some patients are still diagnosed with intermediate (3.1 5.0 $\mathrm{cm}$ in diameter) or large ( $>5.0 \mathrm{~cm}$ in diameter) lesions at presentation. Radiofrequency ablation (RFA) is one of the most popular curative therapies, and the prevailing method of treatment for small HCC lesions [4-6]. The complete ablation rate for small HCC is reported to be more than $95 \%$, with a local recurrence rate $<20 \%$ [7]. However, for intermediate to large HCC, RFA confers lower complete ablation rates ranging from $29 \% \sim 70 \%$ [8]. To widen the scope of RFA, it has been combined with assistant technologies including percutaneous ethanol injection (PEI) and transcatheter arterial chemoembolization (TACE) [912]. Additional innovations could further improve the outcomes of ablation. Currently, conventional US is the

\#Corresponding author: Nan Ya Wang, MD, PhD, Cancer Center of the First Hospital, Jilin University, Jilin 130021, Changchun, China; Tel: +861580430 2611, +8604318878 3984; Fax: +8604318878 3373; Email: nanyawang@yahoo.com. imaging technique most commonly used during RFA. However, it does not provide accurate information about the exact position and vascular flow of the targeted lesions [13]. Contrast-enhanced ultrasound (CEUS) is extremely sensitive to the presence of microbubble agents, thus allowing physicians to evaluate the microvasculature and enhancement patterns of hepatic tumors [14]. Many experimental and clinical studies have indicated that CEUS can be used to evaluate the blood perfusion status of HCC [15-18]. During RFA, CEUS allows the monitoring and multi-angle observation of the targeted lesion, providing objective and accurate information on its position [19]. It is also helpful to detect viable tumor persistence after locoregional therapy, reducing the incidence of local tumor progression and the cost to patients [20,21]. This retrospective case-control study was designed to evaluate the therapeutic efficacy of CEUS in guiding RFA in patients with hepatocellular carcinoma.

\section{Materials and Methods \\ Patients population and study design}

We enrolled 149 patients (116 males and 33 females) who were diagnosed with $\mathrm{HCC}$ and underwent either CEUS- or conventional US-guided RFA. HCC was diagnosed based on either enhanced computed tomography (CT) or magnetic resonance imaging (MRI) scans, or 
pathological evidence. Patients were included in the study if they met the following criteria: (1) maximum tumor diameter $<7.0 \mathrm{~cm}$; (2) three or fewer lesions; (3) Child-Pugh grade $\mathrm{A}$ or $\mathrm{B}$; (4) adequate hematologic function (platelet count $>6 \times 10^{9} / \mathrm{L}$ ). Patients were subsequently allocated into two groups depending on the type of ultrasound guidance they received. The clinical characteristics of the two groups were compared, including sex, age, Child-Pugh grade, tumor size, and tumor number. To further evaluate the Progression-free survival (PFS) and complete ablation rates among patients with tumour size $\geq 3.0 \mathrm{~cm}$, the patients were divided into four groups based on the tumour size and treatment modality, as follows: group 1, tumor size $\geq$ $3.0 \mathrm{~cm}$ treated with CEUS; group 2, tumor size $\geq 3.0 \mathrm{~cm}$ treated with conventional US; group 3, tumour size $<3.0$ $\mathrm{cm}$ treated with CEUS; group 4, tumour size $<3.0 \mathrm{~cm}$ treated with conventional US. Enhanced CT was performed 4 weeks after treatment. Thereafter, the patients were followed up every 3 months. The completely ablated lesions exhibited no enhancement on contrast-enhanced CT. The median follow-up was 10 months (6 21 months).

\section{Contrast agent, CEUS technique and RFA technique}

All patients underwent conventional US prior to RFA treatment to determine the location, number, size, and margins of the tumor(s), and the largest diameter was chosen as the most appropriate plane to display the lesions.

The conventional US group then received conventional US-guided RFA. The other group underwent CEUSguided RFA, and the lesion was observed continuously for $3 \mathrm{~min}$ after the injection of contrast agents to further determine the actual lesion region and scope of ablation scope. All ultrasound evaluations were conducted with a GE LOGIQ9 instrument. The US contrast agent used was a second-generation microbubble, sulphur hexafluoridefilled microbubbles (SonoVue, Bracco, Italy), which were supplied as a lyophilized powder and reconstituted with $5 \mathrm{ml}$ of saline to form a homogeneous micro-bubble suspension. Each injection was administered as a 1.2 2.4 $\mathrm{ml}$ bolus of contrast agent via the antecubital vein within $2 \sim 3 \mathrm{~s}$, followed by a flush with $5 \mathrm{ml}$ of $0.9 \%$ normal saline. The arterial $(8 \sim 30 \mathrm{~s})$, portal venous (31 120 s), and delayed (121 360 s) phases were then monitored in real time. HCC is characteristically hypervascular ion the arterial phase, and washed out during the portal venous phase and delayed phase. CEUS was repeated $5 \mathrm{~min}$ after the ablation to identify any residual arterial phase enhancement and assess the adequacy of the ablation. Incomplete ablation, usually appearing as an irregular or peripheral nodular enhancement in the ablation zone, required repeated procedures until a complete ablation was achieved.

A LDRF-120S multipole radiofrequency ablation instrument was used. Multiple RFA needle electrodes were used to destroy large tumors ( $>5.0 \mathrm{~cm}$ in diameter); single RFA needle electrodes were used to ablate exceptional locations in which multiple needles were difficult to deploy.

\section{Statistical methods}

Statistical analyses were conducted using IBM SPSS 22.0. Categorical and continuous variables were analyzed using the $\chi^{2}$ test and $t$-test, respectively. The PFS was analyzed using the Kaplan-Meier method, and the significance of differences was determined by log-rank analysis. Cox proportional hazards model was used for univariate and multivariate analysis is of risk factors related to the PFS. All $P$ values were two-sided, and $P<0.05$ was considered statistically significant.

\section{Results}

\section{Patient characteristics at baseline}

Among the 149 patients, 74 (49.7\%) and 75 (50.3\%) were in the CEUS and conventional US groups, respectively. Male patients constituted the majority in both groups. There were 58 male patients in each group, and 16 and 17 female patients in the CEUS and conventional US groups, respectively $(P=0.878)$. The mean tumor sizes were $2.46 \pm 0.96(0.7 \sim 5.5) \mathrm{cm}$ and $2.66 \pm 1.12(1 \sim 6.1) \mathrm{cm}$, respectively $(P=0.231)$. There were 59 Child-Pugh grade A cases in the CEUS group and 56 in the conventional US $\operatorname{group}(P=0.462)$. The tumor numbers were comparable between the two groups $(P=0.624)$. No significant differences were observed in the baseline characteristics between the two groups (Table 1).

Table 1 Baseline characteristics of patients in the CEUS and conventional US groups.

\begin{tabular}{|c|c|c|c|}
\hline Variables & $\begin{array}{c}\text { CEUS } \\
(n=74)\end{array}$ & $\begin{array}{c}\text { Conventional } \\
\text { US }(n=75)\end{array}$ & $P$ \\
\hline \multicolumn{4}{|l|}{ Characteristics } \\
\hline \multicolumn{4}{|l|}{ Sex } \\
\hline Male & 58 & 58 & 0.878 \\
\hline Female & 16 & 17 & \\
\hline \multicolumn{4}{|l|}{ Age (years) } \\
\hline$\geq 60$ & 35 & 38 & 0.681 \\
\hline$<60$ & 39 & 37 & \\
\hline \multicolumn{4}{|l|}{ Child-Pugh grade } \\
\hline A & 59 & 56 & 0.462 \\
\hline $\mathrm{B}$ & 15 & 19 & \\
\hline \multicolumn{4}{|c|}{ Maximum HCC size (cm) } \\
\hline$<3.0$ & 50 & 49 & 0.773 \\
\hline$\geq 3.0$ & 24 & 26 & \\
\hline \multicolumn{4}{|l|}{ Tumor number } \\
\hline $1<\mathrm{n} \leq 3$ & 20 & 23 & 0.624 \\
\hline 1 & 54 & 52 & \\
\hline Mean HCC size (cm) & $\begin{array}{c}2.46 \pm 0.96 \\
(0.7 \sim 5.5)\end{array}$ & $\begin{array}{l}2.66 \pm 1.12 \\
\quad(1 \sim 6.1)\end{array}$ & 0.231 \\
\hline
\end{tabular}

HCC, hepatocellular carcinoma; CEUS, contrast-enhanced ultrasound; US: ultrasound 


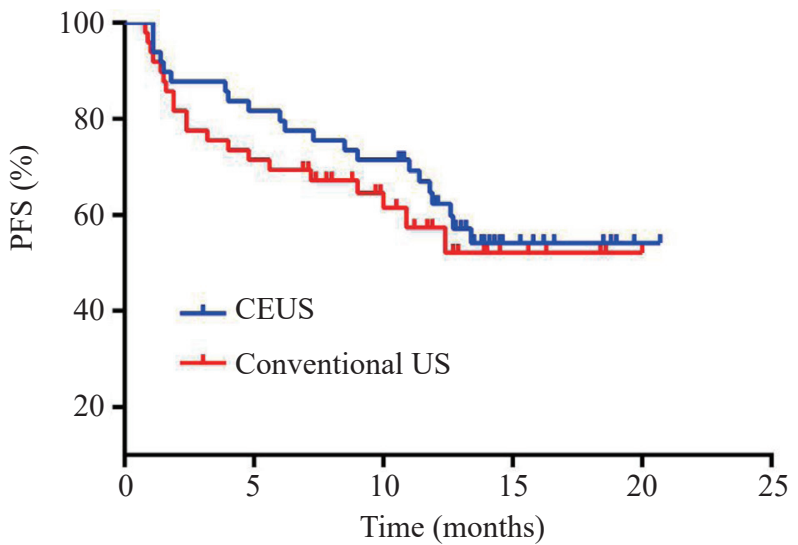

Figure 1 The progression-free survival (PFS) of patients with tumors $<3.0 \mathrm{~cm}$ treated with CEUS- and conventional USguided RFA $(\mathrm{HR}=1.252 ; 95 \% \mathrm{CI}, 0.674 \sim 2.327 ; P=0.474)$.

Comparisons of the PFS and complete ablation rates among the different groups

PFS and complete ablation rates in patients with tumors $<3.0 \mathrm{~cm}$ group

There were $50(67.6 \%)$ and $49(65.3 \%)$ patients with a maximum tumour size $<3.0 \mathrm{~cm}$ in the CEUS and conventional US groups, respectively. The PFS rates are shown in Figure 1. No significant differences in the PFS were noted between the two groups (HR $=1.252 ; 95 \%$ CI, 0.674 2.327; $P=0.474$ ), and median PFS were not reached in either groups. The complete ablation rates in the CEUS group were $92.0 \%, 80.0 \%$, and $70.0 \%$ at $6-, 12-$, and 18-month post-treatment, respectively; the corresponding figures in the conventional US group were $79.6 \%, 77.6 \%$, and $71.4 \%$, respectively. No statistically significant differences were observed in the complete ablation rates between the two groups at $6(P=0.138), 12(P=0.766)$, or 18-month $(P=0.876)$ post-treatment (Table 2$)$.

Table 2 Complete ablation rates at different times posttreatment in patients with tumors $<3.0 \mathrm{~cm}$.

\begin{tabular}{lccc}
\hline Time & CEUS $(\boldsymbol{n}=\mathbf{5 0})$ & Conventional US $(\boldsymbol{n}=\mathbf{4 9 )}$ & $\boldsymbol{P}$ \\
\hline 6 months & $46(92.0 \%)$ & $39(79.6 \%)$ & 0.138 \\
12 months & $40(80.0 \%)$ & $38(77.6 \%)$ & 0.766 \\
18 months & $35(70.0 \%)$ & $35(71.4 \%)$ & 0.876 \\
\hline
\end{tabular}

CEUS, contrast-enhanced ultrasound; US: ultrasound

PFS and complete ablation rates in patients with tumors $\geq 3.0 \mathrm{~cm}$

There were 24 (32.4\%) patients in the CEUS group and $26(34.7 \%)$ in the conventional US group with a maximum tumor size $\geq 3.0 \mathrm{~cm}$. The PFS rates are shown in Figure 2 . Patients who received CEUS had significantly better PFS compared with those who received conventional US (17.3 $\mathrm{m}$ vs 3.1 months, $\mathrm{HR}=2.73 ; 95 \% \mathrm{CI}, 1.28 \sim 5.81 ; P=0.007)$. The complete ablation rates in the CEUS group at 6-, 12-, and 18 -month were $87.5 \%, 75.0 \%$, and $45.8 \%$, respectively, whereas those in the conventional US group were $57.7 \%$, $38.5 \%$, and $34.6 \%$, respectively. Significant differences in complete ablation rates were observed between the two groups at 6- $(P=0.042)$ and 12 -month $(P=0.009)$ posttreatment (Table 3).

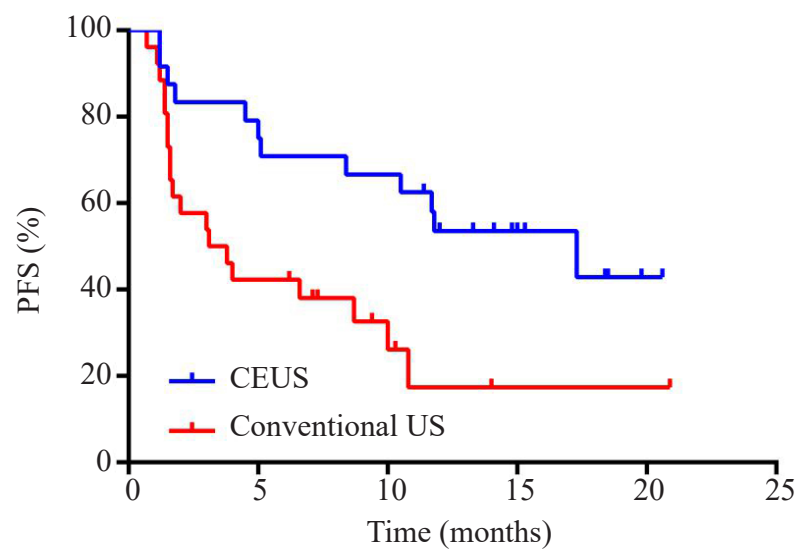

Figure 2 The progression-free survival (PFS) of patients with tumors $\geq 3.0 \mathrm{~cm}$ treated with CEUS- and conventional USguided RFA $(17.3 \mathrm{~m}$ vs 3.1 months, $\mathrm{HR}=2.73 ; 95 \% \mathrm{CI}$, 1.28 5.81; $P=0.007)$.

Table 3 Complete ablation rates at different times posttreatment in patients with tumors $\geq 3.0 \mathrm{~cm}$.

\begin{tabular}{lccc}
\hline Time & CEUS $(\boldsymbol{n}=\mathbf{2 4})$ & $\begin{array}{c}\text { Conventional US } \\
(\boldsymbol{n}=\mathbf{2 6})\end{array}$ & $\boldsymbol{P}$ \\
\hline 6 months & $87.5 \%(21 / 24)$ & $57.7 \%(15 / 26)$ & 0.042 \\
12 months & $75.0 \%(18 / 24)$ & $38.5 \%(10 / 26)$ & 0.009 \\
18 months & $45.8 \%(11 / 24)$ & $34.6 \%(9 / 26)$ & 0.419 \\
\hline
\end{tabular}

CEUS, contrast-enhanced ultrasound; US: ultrasound

\section{Factors that affect the PFS}

The univariate analysis identified that the use of conventional US $(\mathrm{HR}=1.655,95 \% \mathrm{CI}, 1.032 \sim 2.652$, $P=0.036)$ and a maximum tumour size $\geq 3.0 \mathrm{~cm}$ in diameter $(\mathrm{HR}=1.768,95 \% \mathrm{CI}, 1.108 \sim 2.823, P=0.017)$ were significant factors associated with a lower PFS. In a multivariate analysis, the use of conventional US (HR = $1.732,95 \% \mathrm{CI}, 1.077 \sim 2.786, P=0.024)$ and a maximum tumour size $\geq 3.0 \mathrm{~cm}$ in diameter $(\mathrm{HR}=1.844,95 \% \mathrm{CI}$, 1.152 2.949, $P=0.011$ ) were both found to be risk factors for a decreased PFS (Table 4).

\section{Recurrence}

Distant recurrence was defined as the emergence of a tumor not adjacent to the ablation zone and local recurrence was defined as a reappearance of tumor progression adjacent to the treated site. During the follow-up, the 1-, 6and 12-month local recurrence rates for the CEUS and the conventional US groups were $0 \%, 9.5 \%$, and $21.6 \%$ and $6.7 \%$, $28.0 \%$, and $36.0 \%$, respectively. The corresponding distant recurrence rates for the 2 groups were $0 \%, 12.2 \%$, and $23.0 \%$ and $0 \%, 13.3 \%$, and $20.0 \%$, respectively (Table 5). 
Table 4 Results of the univariate and multivariate analyses of the risk factors for the progression free survival (PFS).

\begin{tabular}{|c|c|c|c|c|}
\hline \multirow[t]{2}{*}{ Variables } & \multicolumn{2}{|c|}{ Univariate analysis } & \multicolumn{2}{|c|}{ Multivariate analysis } \\
\hline & HR (95\% CI) & $\boldsymbol{P}$ & HR (95\% CI) & $P$ \\
\hline Age $(\geq 60$ vs $<60$ y) & $1.150(0.723 \sim 1.828)$ & 0.555 & & \\
\hline Type of treatment (US vs CEUS) & $1.655(1.032 \sim 2.652)$ & 0.036 & $1.732(1.077 \sim 2.786)$ & 0.024 \\
\hline Child-Pugh class (B vs A) & $0.870(0.499 \sim 1.518)$ & 0.624 & & \\
\hline Tumor number (multiple vs single) & $1.277(0.778 \sim 2.097)$ & 0.333 & & \\
\hline Maximum tumor size $(\geq 3.0 \mathrm{vs}<3.0 \mathrm{~cm})$ & $1.768(1.108 \sim 2.823)$ & 0.017 & $1.844(1.152 \sim 2.949)$ & 0.011 \\
\hline
\end{tabular}

CEUS, contrast-enhanced ultrasound; US: ultrasound

Table 5 Recurrence rates at different times post-treatment in the CEUS-guided and conventional US-guided groups

\begin{tabular}{lcc}
\hline Group & $\begin{array}{c}\text { Local recurrence } \\
(\mathbf{\%})\end{array}$ & $\begin{array}{c}\text { Distant recurrence } \\
(\mathbf{\%})\end{array}$ \\
\hline CEUS & & 0 \\
1 month & 0 & $12.2(9 / 74)$ \\
6 months & $9.5(7 / 74)$ & $23.0(17 / 74)$ \\
12 months & $21.6(16 / 74)$ & 0 \\
Conventional US & & $13.3(10 / 75)$ \\
1 month & $6.7(5 / 75)$ & $20.0(15 / 75)$ \\
6 months & $28.0(21 / 75)$ & \\
12 months & $36.0(27 / 75)$ & \\
\hline
\end{tabular}

CEUS, contrast-enhanced ultrasound; US: ultrasound

\section{Discussion}

RFA is a safe and effective approach for treating small hepatic tumors, and is associated with a 5-year survival rate higher than $50 \%[22,23]$. Imaging-based guidance has an important role in RFA for HCC by ensuring accuratein targeting of the lesion and in assessing the efficacy of the ablation. Despite advances in computed tomography (CT) and magnetic resonance imaging (MRI), US continues to be the most commonly performed imaging technique during the treatment of HCC due to its low cost, availability and lack of radiation exposure. Unfortunately, conventional US may provide insufficient detection and characterization of liver lesions. In particular, the identification of residual disease is often difficult. In most cases, conventional US cannot distinguish viable tumor from necrotic tissue in the treated area [22]. Therefore, at the end of treatment, conventional US cannot precisely assess the size and completeness of coagulation-induced necrosis. Many researchers have noted that the therapeutic effects of RFA decreased as the tumor size increased. For example, Livraghi T et al. [24] reported that the RFA-induced complete tumor necrosis rates was $90 \%, 71 \%$, and $25 \%$ for tumors $\leq 3.0 \mathrm{~cm}, 3.1 \sim 5.0 \mathrm{~cm}$, and $>5.0 \mathrm{~cm}$, respectively. Liang $\mathrm{HH}$ et al. [25] demonstrated that the 1-, 2-, and 3-year overall survival rates of patients with tumors $\leq 3.0 \mathrm{~cm}$ after RFA were higher than those with tumors $3.1 \sim 5.0 \mathrm{~cm}$ and $>5.0 \mathrm{~cm}$. The results of our present study also revealed that the complete ablation rates decreased as tumor size increased. These drawbacks have prevented the widespread use of RFA in treating intermediate- to large-sized hepatic tumors. In our study, there were no significant differences in the complete ablation rates between the conventional US and CEUS in patients with tumors $<3.0 \mathrm{~cm}$. This is likely because small HCC can often be successfully treated by conventional US-guided RFA, with efficacy almost the same as that of surgical resection. Thus, it is difficult to further improve the results of RFA for small tumors [26-28]. In contrast, for tumors $\geq 3.0 \mathrm{~cm}$, the complete ablation rates were higher in the CEUS group than in the conventional US group at 6 and 12 months' post-treatment. This suggests that CEUS-guided RFA may be more effective in treating HCC $\geq 3.0 \mathrm{~cm}$ compared with conventional US-guided RFA.

Using CEUS with a second-generation contrast agent provides an excellent visualization of both microvascularization and the overall perfusion patterns of liver lesions. It is easily performed and can be repeated as needed because microbubbles are associated with a low risk of adverse events, lower than the risks of contrast agents used in CT or MRI scans [29]. Several studies have shown that CEUS has the ability to characterize HCC lesions, in addition to guiding RFA treatment [30]. It plays a pivotal role both before and during RFA treatment by permitting real-time vascular imaging with high spatial and temporal resolution. Before RFA, real-time targeting under the guidance of CEUS has been used to facilitate accurate needle positioning and precisely target the areas that require treatment [31]. During ablation treatments, CEUS can be used to identify residual areas of enhancement, with the possibility of immediately performing re-treatment within the same session. This application has been shown to reduce the number of failed radiofrequency procedures and decrease the rate of incomplete ablation from $16 \%$ to $6 \%$ [32, 33].

In our study, the PFS of patients who received CEUS were longer than those of patients who received conventional US (17.3 vs 3.1 months, $P=0.007$ ) among those with tumors $\geq 3.0 \mathrm{~cm}$. The complete ablation rates were significantly higher in patients with tumors $\geq 3.0 \mathrm{~cm}$ treated with CEUS-guided RFA than in those treated with conventional US-guided RFA at 6- and 12- month post- 
treatment $(87.5 \%$ vs $57.7 \%, P=0.042 ; 75.0 \%$ vs $38.5 \%$, $P=0.009$, respectively). And another study has revealed that the complete ablation rates of the group treated with CEUS-guided RFA were significantly higher than those of the conventional US-guided group at the 1-month followup $(90.5 \%$ vs $52.4 \%, P=0.017)$ [34]. The univariate and multivariate analyses in our study suggested that the type of treatment and maximum tumor size were significant factors affecting the PFS. HCC $\geq 3.0 \mathrm{~cm}$ was a risk factor for a shorter PFS (HR $=1.844, P=0.011)$. Compared with conventional US, CEUS-guided RFA could improve the PFS (HR $=1.732, P=0.024)$, especially for patients with tumors $\geq 3.0 \mathrm{~cm}$. We believe that this is because CEUS can more easily detect HCC lesions by confirming the area of enhancement, making it possible to ensure that there is a sufficient ablative margin during RFA. One study found that the enhanced area of HCC detected using CEUS was larger than that measured by conventional US in $40 \% \sim 60 \%$ patients, which indicates that CEUS can more better reflect the actual condition of the tumor and more accurately determine the appropriate range of RFA [35]. In brief, RFA guided by CEUS can help to confirm that there is a sufficient ablation margin, which is critical for preventing the local recurrence of $\mathrm{HCC} \geq 3.0 \mathrm{~cm}$.

\section{Conclusion}

This study indicated that the therapeutic efficacy of RFA guided by CEUS was better than that of RFA guided by conventional US in patients with hepatocellular carcinoma $\geq 3.0 \mathrm{~cm}$.

\section{Conflict of Interest}

The authors declare that there is no conflicts of interest.

\section{Funding}

This work was supported by the Training Plan for Outstanding Young Teachers of Jilin University (No. 419080500356).

\section{References}

1. Bray F, Ferlay J, Soerjomataram I, Soerjomataram I, Siegel RL, Torre LA, Jemal A. Global cancer statistics 2018: GLOBOCAN estimates of incidence and mortality worldwide for 36 cancers in 185 countries. CA Cancer J Clin 2018;68(6):394-424.

2. Chen W, Zheng R, Baade PD, Zhang S, Zeng H, Bray F, Jemal A, Yu XQ, He J. Cancer statistics in China, 2015. CA Cancer J Clin 2016;66(2):115-32.

3. Renzulli M, Tovoli F, Clemente A, Ierardi AM, Pettinari I, Peta G, Marasco G, Festi D, Piscaglia F, Cappabianca S, Carrafiello G, Golfieri R. Ablation for hepatocellular carcinoma: beyond the standard indications. Med Oncol 2020;37(4):23.

4. Zhang YJ, Liang HH, Chen MS, Guo RP, Li JQ, Zheng Y, Zhang YQ, Lau WY. Hepatocellular carcinoma treated with radiofrequency ablation with or without ethanol injection: a prospective randomized trial. Radiology 2007;244(2):599-607.

5. Yu SCH, Hui JWY, Chong CCN, Chu CM, Cheung S, Wong J, Lee KF. Transarterial ethanol ablation for small hepatocellular carcinoma ( $\leq$ $3 \mathrm{~cm}$ ): a comparative study versus radiofrequency ablation. Cardiovasc Intervent Radiol 2020;43(5):732-9.

6. Omata M, Cheng AL, Kokudo N, Kudo M, Lee JM, Jia J, Tateishi R, Han KH, Chawla Y K, Shiina S, Jafri W, Payawal DA, Ohki T, Ogasawara S, Chen PJ, Lesmana CRA, Lesmana LA, Gani RA, Obi S, Dokmeci AK, Sarin SK. Asia-Pacific clinical practice guidelines on the management of hepatocellular carcinoma: a 2017 update. Hepatol Int 2017;11(4):317-70.

7. Vigano L, Laurenzi A, Solbiati L, Procopio F, Cherqui D, Torzilli G. Open liver resection, laparoscopic liver resection, and percutaneous thermal ablation for patients with solitary small hepatocellular carcino$\mathrm{ma}(\leq 30 \mathrm{~mm})$ : review of the literature and proposal for a therapeutic strategy. Dig Surg 2018;35(4):359-71.

8. Morimoto M, Numata K, Kondou M, Nozaki A, Morita S, Tanaka K. Midterm outcomes in patients with intermediate-sized hepatocellular carcinoma: a randomized controlled trial for determining the efficacy of radiofrequency ablation combined with transcatheter arterial chemoembolization. Cancer 2010;116(23):5452-60.

9. Lencioni RA, Allgaier HP, Cioni D, Olschewski M, Deibert P, Crocetti L, Frings H, Laubenberger J, Zuber I, Blum HE, Bartolozzi C. Small hepatocellular carcinoma in cirrhosis: randomized comparison of radio-frequency thermal ablation versus percutaneous ethanol injection. Radiology 2003;228(1):235-40.

10. Min JH, Lee MW, Rhim H, Choi D, Kim YS, Kim YJ, Cha DI, Lim HK. Recurrent hepatocellular carcinoma after transcatheter arterial chemoembolization: planning sonography for radio frequency ablation. J Ultrasound Med 2011;30(5):617-24.

11. Kurokohchi K, Masaki T, Himoto T, Deguchi A, Nakai S, Yoneyama H, Yoshida S, Kimura Y, Inoue H, Kinekawa F, Yoshitake A, Izuishi K, Watanabe S, Kuriyama S. Successful laparoscopic radiofrequency ablation of hepatocellular carcinoma adhered to the mesentery after transcatheter arterial embolization. Oncol Rep 2005;13(1):65-8.

12. Yan $S, X u$ D, Sun B. Combination of radiofrequency ablation with transarterial chemoembolization for hepatocellular carcinoma: a meta-analysis. Dig Dis Sci 2013;58(7):2107-13.

13. Dong Y, Wang WP, Gan YH, Huang BJ, Ding H. Radiofrequency ablation guided by contrast-enhanced ultrasound for hepatic malignancies: preliminary results. Clin Radiol 2014;69(11):1129-35.

14. Kim AY, Lee MW, Rhim H, Cha DI, Choi D, Kim YS, Lim HK, Cho SW. Pretreatment evaluation with contrast-enhanced ultrasonography for percutaneous radiofrequency ablation of hepatocellular carcinomas with poor conspicuity on conventional ultrasonography. Korean J Radiol 2013;14(5):754-63.

15. Doury M, Dizeux A, de Cesare A, Lucidarme O, Pellot-Barakat C, Bridal SL, Frouin F. Quantification of tumor perfusion using dynamic contrast-enhanced ultrasound: Impact of mathematical modeling. Phys Med Biol 2017;62(3):1113-25.

16. Zhang P, Chen Y, Liu J, Yang Y, Lv Q, Wang J, Zhang L, Xie M. Quantitative evaluation of combretastatin A4 phosphate early efficacy in a tumor model with dynamic contrast-enhanced ultrasound. Ultrasound Med Biol 2018;44(4):840-52. 
17. Delorme S, Krix M. Contrast-enhanced ultrasound for examining tumor biology. Cancer Imaging 2006;6(1):148-52.

18. Lo GM, Al Zahrani H, Jang HJ, Menezes R, Hudson J, Burns P, McNamara MG, Kandel S, Khalili K, Knox J, Rogalla P, Kim TK. Detection of early tumor response to axitinib in advanced hepatocellular carcinoma by dynamic contrast enhanced ultrasound. Ultrasound Med Biol 2016;42(6):1303-11.

19. Wu H, Wilkins LR, Ziats NP, Haaga JR, Exner AA. Real-time monitoring of radiofrequency ablation and postablation assessment: accuracy of contrast-enhanced US in experimental rat liver model. Radiology 2014;270(1):107-16.

20. Meloni MF, Andreano A, Franza E, Passamonti M, Lazzaroni S. Contrast enhanced ultrasound: Should it play a role in immediate evaluation of liver tumors following thermal ablation? Eur J Radiol 2012;81(8):e897-902.

21. Mauri G, Porazzi E, Cova L, Restelli U, Tondolo T, Bonfanti M, Cerri A, Ierace T, Croce D, Solbiati L. Intraprocedural contrast-enhanced ultrasound (CEUS) in liver percutaneous radiofrequency ablation: clinical impact and health technology assessment. Insights Imaging 2014;5(2):209-16

22. Dohmen T, Kataoka E, Yamada I, Miura K, Ohshima S, Shibuya T, Segawa D, Sato W, Anezaki, Y, Ishii H, Kamada K, Goto T, Ohnishi H. Efficacy of contrast-enhanced ultrasonography in radiofrequency ablation for hepatocellular carcinoma. Intern Med 2012;51(1):1-7.

23. Takai Takamatsu R, Okano A, Yamakawa G, Mizukoshi K, Obayashi H, Ohana M. Impact of an ultrasound-guided radiofrequency ablation training program on the outcomes in patients with hepatocellular carcinoma. Diagn Interv Imaging 2019;100(12):771-80.

24. Livraghi T, Lazzaroni S, Meloni F. Radiofrequency thermal ablation of hepatocellular carcinoma. Eur J Ultrasound 2001;13(2):159-66.

25. Liang HH, Chen MS, Wang XD, Zhang YQ, Zheng Y, Li JQ. Analysis of the therapeutic efficiency of percutaneous radiofrequency ablation on hepatocellular carcinomas. Zhonghua Gan Zang Bing Za Zhi 2004;12(12):756-7.

26. Chen MS, Li JQ, Zheng Y, Guo RP, Liang HH, Zhang YQ, Lin XJ,
Lau WY. A prospective randomized trial comparing percutaneous local ablative therapy and partial hepatectomy for small hepatocellular carcinoma. Ann Surg 2006;243(3):321-8

27. Peng ZW, Chen MS, Liang HH, Gao HJ, Zhang YJ, Li JQ, Zhang YQ, Lau WY. A case-control study comparing percutaneous radiofrequency ablation alone or combined with transcatheter arterial chemoembolization for hepatocellular carcinoma. Eur J Surg Oncol 2010;36(3):257-63

28. Zhu ZX, Huang JW, Liao MH, Zeng Y. Treatment strategy for hepatocellular carcinoma in China: radiofrequency ablation versus liver resection. Jpn J Clin Oncol 2016;46(12):1075-80.

29. Cantisani V, Wilson SR. CEUS: where are we in 2015? Eur J Radiol 2015;84(9):1621-2.

30. Chan AK, Hegarty C, Klass D, Yoshida E, Chung S, Liu DM, Ho SG, Harris AC. The Role of contrast-enhanced ultrasound in guiding radiofrequency ablation of hepatocellular carcinoma: a retrospective study. Can Assoc Radiol J 2015;66(2):171-8.

31. Solbiati L, Ierace T, Tonolini M, Cova L. Guidance and monitoring of radiofrequency liver tumor ablation with contrast-enhanced ultrasound. Eur J Radiol 2004;51 Suppl:S19-23.

32. Kim TK, Khalili K, Jang HJ. Local ablation therapy with contrast-enhanced ultrasonography for hepatocellular carcinoma: a practical review. Ultrasonography 2015;34(4):235-45

33. Durot I, Wilson SR, Willmann JK. Contrast-enhanced ultrasound of malignant liver lesions. Abdom Radiol (NY) 2018;43(4):819-47.

34. Lu SC, Ren QH, Huang Q, Lu HM. Therapeutic effect comparison of radiofrequency ablation guided by conventional ultrasound and contrast-enhanced ultrasound in patient with advanced primary liver cancer following transcatheter arterial chemoembolization J. Chinese Journal of Bases and Clinics in General Surgery 2018;25(11):1318-22.

35. Yan K, Chen MH, Zhang XM, Gao W, Yang W, Zhang H, Fu Y, Wu W. Radiofrequency ablation of small hepatic malignancies guided by contrast enhanced ultrasonography J. Chinese Journal of Ultrasonography 2011;20(1):18-21. 